\title{
Coping strategies used by poorly adherent patients for self-managing bipolar disorder
}

\author{
This article was published in the following Dove Press journal: \\ Patient Preference and Adherence \\ 25 July 2016 \\ Number of times this article has been viewed
}

\section{Carol Blixen ${ }^{1,2}$ \\ Jennifer B Levin ${ }^{2}$ \\ Kristin A Cassidy ${ }^{2}$ \\ Adam T Perzynski' \\ Martha Sajatovic ${ }^{2-4}$ \\ 'Center for Health Care Research and Policy, MetroHealth Medical \\ Center, ${ }^{2}$ Department of Psychiatry, ${ }^{3}$ Department of Neurology, \\ Neurological Institute, ${ }^{4}$ Department of Biostatistics \& Epidemiology, University Hospitals Case Medical Center, Case Western Reserve University School of Medicine, Cleveland, OH, USA}

Background: Bipolar disorder (BD) is a chronic mental illness associated with reduced quality of life, high rates of suicide, and high financial costs. Evidence indicates that psychosocial stress might play an important role in the onset and course of BD.

Objective: The objective of this study was to address the gap between coping theory and the clinical use of coping strategies used to self-manage BD.

Methods: In-depth interviews were conducted with a sample of 21 poorly adherent patients with BD. All interviews were audiotaped, transcribed verbatim, and analyzed using content analysis with an emphasis on dominant themes.

Results: Transcript-based analysis generated two major domains of coping strategies used to self-manage BD: 1) problem focused (altering eating habits, managing mood-stabilizing medications, keeping psychiatric appointments, seeking knowledge, self-monitoring, and socializing) and 2) emotion focused (distracting activities, denial, isolation, modifying/avoiding, helping others, and seeking social support). Participants used both types of coping strategies to deal with stressful situations brought about by the internal and external demands associated with self-management of BD.

Conclusion: This qualitative study provided a first step in evaluating coping strategies as a possible mediator in the self-management of $\mathrm{BD}$ and has implications for health care providers. Being able to characterize an individual's coping behaviors can help patients modify or replace more maladaptive coping with better coping strategies in the self-management of this chronic mental illness.

Keywords: bipolar disorder, coping strategies, self-management

\section{Introduction}

Bipolar disorder (BD) is a chronic mental illness associated with reduced quality of life and functioning, high rates of suicide, and high financial costs. ${ }^{1}$ Prevalence in the USA may be as high as $3.7 \%$ for BD type I and II and is associated with psychosocial consequences that have devastating effects on families and children., ${ }^{2,3}$ A cornerstone of treatment for individuals with BD is mood-stabilizing medications, such as lithium, anticonvulsants, or atypical antipsychotic medication, ${ }^{3-6}$ yet approximately one in two individuals with BD are nonadherent with medication. ${ }^{7}$ A recent review of 78 research papers on psychosocial interventions as an adjunct to the efficacy of medication suggests that adjunctive psychological treatment can improve specific illness outcomes, but such interventions should be applied as early as possible and should be tailored to the specific needs of the patient. ${ }^{8}$ Most psychosocial interventions involve the integration of cognitive, behavioral, and biological components to help patients cope with life's demands, which are appraised as stressful. ${ }^{9,10}$
Correspondence: Carol Blixen Center for Health Care Research \& Policy, MetroHealth Medical Center, Case Western Reserve University, 2500 MetroHealth Drive, Cleveland, OH, USA Tel +l 2162834134 Email cxb28@cwru.edu 
Stress and coping have been identified as important variables affecting health. ${ }^{11,12}$ The way in which people manage stress can both reduce and enhance the effects of stressful life events and adverse conditions. ${ }^{13}$ Evidence indicates that psychosocial stress might play an important role in the onset and course of BD. ${ }^{14}$ According to a recent pathophysiological model of $\mathrm{BD}$, coping abilities might play a role in modulating the relationship between stress and episodic recurrence, which can be directly affected by neurofunctional and neurostructural damage associated with a recurrent course of BD. ${ }^{15}$ However, there is a paucity of research on the coping strategies used by poorly adherent patients with $\mathrm{BD}$ in self-managing their chronic illness. To help address this gap, the present study assessed perceived coping strategies for the self-management of $\mathrm{BD}$ among highrisk patients as part of a large, on-going US National Institutes of Mental Health-funded randomized controlled trial (RCT) of a customized adherence enhancement intervention versus broadly directed, nonindividualized education. Our qualitative findings have the potential to enrich our understanding of the coping processes that are personally salient for individuals with $\mathrm{BD}$ and may help clinicians and researchers integrate these factors into effective care delivery practices.

\section{Methods}

\section{Sample and setting}

Participants $(\mathrm{N}=21)$ from the RCT were recruited for the present analysis. For qualitative research, this sample size is within the recommended number of 5-25 individuals who have all experienced the same phenomena. ${ }^{16} \mathrm{~A}$ sampling grid designed to ensure variability in sex, age, and race/ethnicity was used in the recruitment of participants. Nonadherence was assessed as the percentage of days with missed doses in the past week for each prescribed foundational oral medication for the treatment of BD. For individuals who were on $\geq 1$ foundational medication, an average was calculated to gather information on the full BD treatment regimen. We did not measure the level of adherence to antidepressant drugs as they are often prescribed sporadically to target acute symptoms and are not considered to be maintenance medication for BD. For individuals who reported being prescribed nonpsychiatric medication, the percentage of days with missed doses was calculated for each medication separately and then an average tariff-rate quota for all nonpsychiatric medications was then calculated. Higher tariff-rate quota scores are a reflection of worse medication adherence.

The mean age of the respondents was 47.29 years (standard deviation $[\mathrm{SD}]=11.06), 15(71.4 \%)$ were women and the mean level of education was 12.10 years $(\mathrm{SD}=2.31)$. Only $3(14.3 \%)$ were married, and 18 (85.7\%) were disabled or unemployed. Thirteen (61.9\%), identified themselves as African-American, five (23.8\%) as Caucasian, one (4.8\%) as Hispanic, and three (14.3\%) as Other. Seventeen (81.0\%) had type I BD and three (14.3\%) had type II BD. Average age of onset was 22.05 ( $\mathrm{SD}=10.31$ ), and average number of psychiatric hospitalizations was $4.15(\mathrm{SD}=3.47)$.

The study was conducted in the Department of Psychiatry of University Hospitals in Northeast Ohio. The study was approved by The University Hospitals Institutional Review Board, FWA00003937, protocol number 02-12-04. All participants provided written informed consent.

\section{Theoretical framework}

Lazarus and Folkman's Transactional Theory of Stress and Coping ${ }^{17,18}$ was used as a framework for the present research. In this transaction-based model, coping is viewed as a process-oriented phenomenon and comprises four essential definitions: 1) coping is a process or interaction between the individual and environment; 2) coping mechanisms likely manage a stressful situation rather than control or overcome it; 3 ) the coping process comprises the notion of evaluation (how individuals perceive, interpret the phenomenon); and 4) the coping process involves efforts to manage, reduce, or endure internal demands that are appraised as exceeding the resources of the person. Efforts to ameliorate the perceived threat or to manage stress are conceptualized as either problem-focused coping (direct action) or emotion-focused coping (palliative). In this framework of stress and coping, it is not uncommon to use both types of coping strategies to deal with stressful situations brought about by internal and external demands.

\section{Study design}

In this exploratory/observational study, a phenomenological approach ${ }^{19}$ was used to develop a deeper understanding of the coping strategies that patients who are treatment nonadherent manage their BD. In this approach, the meaning of the lived experiences of a concept or phenomenon for an individual is described. In this case, the phenomenon under study is "how" nonadherent individuals with BD cope with managing their chronic illness. Data collection in phenomenological studies consists of individual in-depth interviews with participants. ${ }^{19}$ The goal of in-depth interviews is to explore a topic openly and to allow interviewees to express their opinions and ideas in their own words. Therefore, participants were given as much latitude as possible to describe their lived experience of 
coping with self-management of their BD. In-depth interviews are an appropriate strategy for learning the vocabulary and thinking patterns of the target audience as well as for discovering unanticipated findings and exploring hidden meanings.

\section{Qualitative data collection and analysis}

These interviews (conducted as part of the baseline assessment in the RCT) explored perceived coping strategies that helped patients self-manage their BD as well as ideas about how health care providers could support them in this task. A semistructured interview guide focused the discussion on main topics and specific topic-related questions. For example, under the topic, "coping strategies to help with managing BD", the following open-ended question was asked: "What sort of things help you in managing your BD?" Under the topic, "What can your health care provider do to help you manage BD", the following question was asked: "If you had 10 minutes to speak to your provider about what he/she could do to help you to better manage your $\mathrm{BD}$, what would you tell them?" The guide also included some examples of follow-up questions or probes such as "Would you explain further", "Please describe what you mean", and "Would you give me an example?" Two investigators ( $\mathrm{CB}$ and $\mathrm{AP}$ ) conducted the qualitative interviews, which took approximately 45-60 minutes. The use of two interviewers gave the investigators an opportunity to meet and compare notes, thus giving more scope for interpretation and minimizing problems with transcription.

In qualitative research, data collection, coding, and analysis occur simultaneously rather than sequentially. Emerging insights can be incorporated into later stages of data generation, enhancing the comprehensiveness of the results. ${ }^{20}$ Interview audiotapes were transcribed verbatim and analyzed using the classic method of content analysis with an emphasis on dominant themes. ${ }^{21}$ Themes were identified by a descriptive label, which helped to organize the text within and between transcripts for comparison. ${ }^{22}$

A coding manual to list codes and their definitions were modified iteratively. After descriptive coding, all transcripts were reviewed using the final coding manual to ensure that all possible codes had been applied. These code-based files contained all coded text for each code across all respondents and were reviewed and discussed to further elaborate, refine, and differentiate the codes and to identify similarities and differences. The significant statements and themes attached to the codes were then used to write a textural description of what participants experienced. They were also used to write a description of the context or setting that influenced how the participants experienced the phenomenon called imaginative variation or structural description. ${ }^{23}$ Reduction of data in this manner enabled us to write a composite description that represented the essence of the phenomenon (perceptions of "how") medication nonadherent individuals with BD cope with self-managing their disease.

\section{Results}

Transcript-based analysis generated two major domains of coping strategies used by high-risk patients with BD in self-managing their illness: 1) problem-focused coping strategies that encompass efforts to define the problem, generate alternative solutions, weigh the costs and benefits of various actions, and take actions to change what is changeable and 2) emotion-focused coping strategies that are directed at decreasing emotional distress. Unlike problem-focused strategies, emotion-focused strategies do not change the meaning of a situation directly. ${ }^{17,18}$

Table 1 shows themes, descriptive codes, and illustrative quotations emerging from the discussion on coping with self-management of BD. These coping strategies were classified into six categories that reflected problem-focused efforts directed at altering some aspect of the environment, or self, associated with managing BD: 1) altering lifestyle behaviors, 2) managing mood-stabilizing medications, 3) keeping psychiatric appointments, 4) seeking knowledge on $\mathrm{BD}, 5$ ) socializing, and 6) self-monitoring.

\section{Altering lifestyle behaviors Changing eating habits}

Eating healthier was a coping strategy used by some respondents to improve their nutritional intake and overall health:

As far as eating, doing a lot of cutting back of meat, junk food - things of that nature, cause it's not good. Cutting out sugars. I don't do a lot of dairy. Do a lot of fruits and vegetables. A lot of raw fruits and vegetables. And lemon and, you know, sodas and juices and things of that nature. [Respondent \#2011]

Others exercised to improve mobility and flexibility:

I do leg lifts and do my arm exercises. They're really not doing any good. I do this mostly to keep my muscle strengths together, so that I can still maintain a small ability to be able to walk. The mobility factor. To be able to get in and out of the wheel chair. [Respondent \#2093]

I exercise every day. Not vigorous activity, but stretching and sit-ups and things of that nature. [Respondent \#2011] 
Table I Problem-focused coping strategies for self-management among poorly adherent patients with $B D(N=2 I)$

\begin{tabular}{|c|c|}
\hline Themes and categories & Illustrative quotations from respondents \\
\hline Altering eating habits & $\begin{array}{l}\text { "I was eating a lot of junk food and sugar and wondering why I couldn't sleep and it's like all that sugar and } \\
\text { stuff so what I did is I changed my diet. I started like eating like more fruits and vegetables, I try not to drink } \\
\text { coffee after five o'clock, I try to eliminate sugar all together now once in a while I might get like a candy bar or } \\
\text { something but as far as putting sugar in my food or my coffee, no. I use, a substitute”. [Respondent \#2006] }\end{array}$ \\
\hline Managing mood stabilizing meds & $\begin{array}{l}\text { "I have my medicine right by my bed and then what I do is I have a bottle of water by my bed and my medicine is } \\
\text { right by my bed, so as soon as I sit up I take them". [Respondent \#2008] }\end{array}$ \\
\hline Keeping psychiatric appointments & “[...] nowadays I try and keep my appointments pretty good. Uh, pretty much all the time". [Respondent \#2020] \\
\hline Seeking knowledge on BD & $\begin{array}{l}\text { "The written instructions have been very helpful too, it explains everything and shows you precautions and the } \\
\text { uh-uh the overdose and interactions and all the other kind of stuff you know. So it it's been very clear to me". } \\
\text { [Respondent \#2009] }\end{array}$ \\
\hline Socializing & $\begin{array}{l}\text { "I visit my mom, and my sister comes like maybe once or twice out of the month and then we get um movies } \\
\text { and we buy junk food and watch movies and eat junk food". [Respondent \#2006] }\end{array}$ \\
\hline Self-monitoring & $\begin{array}{l}\text { “I monitor myself. Now it's like, before I do stuff, I try to, like, say “Do you really think that's a good idea?” Like, } \\
\text { um, I only need twenty-eight more credits to graduate. So, l'm like, should I take fifteen credits so I can just } \\
\text { hurry up and be done. [S chuckles] But do you really think that you could really sit down and do fifteen credit } \\
\text { hours. That's uh, that's how I ask myself questions now”. [Respondent \#20I5] }\end{array}$ \\
\hline
\end{tabular}

Abbreviation: $\mathrm{BD}$, bipolar disorder.

However, the onset of a depressive episode, after a period of mood elevation, often curtailed efforts to continue with an exercise routine:

I was exercising a lot sometime before the past three weeks when I got depressed. I had some kind of energy. I had a lot of energy. [Respondent \#2013]

\section{Managing mood-stabilizing drugs}

\section{Remembering bad experiences}

Recalling periods in their lives when they were nonadherent with medications was another coping strategy used to get them back on the self-management track:

Well just remembering things that happened to me in the past when I didn't take my meds and reverted to taking drugs and not wanting to get caught up in the madness again. [Respondent \#2008]

\section{Keeping to a schedule}

Taking mood-stabilizing medications at the same times every day was a coping strategy used by some respondents:

I took them twice a day. As soon as I got up, I'd have something to eat, and then take them. And then I'd take them, uh, before bedtime. So, staying on schedule wasn't a problem. [Respondent \#2017]

\section{Reminders/prompts}

Also, using "reminders/prompts" to help with remembering to take medication for BD was another self-monitoring method of coping with self-management:
Yes, the only thing that has been helping me is I put the bottle, like, right on my window sill. And, you know, you can't help but to see it. If I leave it sitting in the cabinet, I might forget about it. But if I leave it sitting there in my plain view of my eye sight, I'm gonna walk past and look at it and say "Oh, yeah. Make sure you take your pill today." I mean, it's just kind of crazy, because I got three kids in the house and school work, and then, I'm just going about my day and I just walk past the bottle and I'm like $\mathrm{OH}$, YEAH. [Respondent \#2020]

\section{Keeping psychiatric appointments}

Overall, respondents reported trying to keep appointments with their psychiatric providers:

Oh, yeah, I keep my appointments except when she's on vacation or something like that. No, I never miss them but maybe a couple of times and she always said if I had a crisis I can call this emergency crisis hotline or call her. [Respondent \#2003]

At first it was every month, but they feel like I'm being I'm stabilized enough and she felt that being on the medicine and stuff and talking to me and not have any problems, so now it's very other month. [Respondent \#2006]

\section{Seeking knowledge on BD}

\section{Internet}

Increasing knowledge about $\mathrm{BD}$, either by reading the instructions that came with their medications, or using the internet, was reported as being helpful in coping with managing $\mathrm{BD}$ : 
I've done a lot of research on it. Like on the internet. Like I searched what is bipolar disorder, and how does it affects you. I've got tons of research on that and it's helped me understand. There's chat rooms, and people in there blogging about their experiences that they have with it. And how they manage to cope with it. It was all types of stuff. It is helpful, because it makes me feel like I'm not alone, you know. What I can do to better manage it, and it's not so bad that I have it. So, I don't feel so bad about it. [Respondent \#2015]

\section{Socializing}

Socializing with family and friends was a conscious effort by some to cope with the isolation that often comes with BD:

I work every day but I do a few things at home or like walk, see friends, or do things with family. Pretty much staying active, talking to people, enjoying life more. [Respondent \#2017]

\section{Self-monitoring}

Monitoring their thoughts and actions was a coping strategy used by some respondents in facing the, sometimes, onerous task of managing their BD.

\section{Self-talk}

Talking to oneself about how to slow down and think things through was one method used to self-monitor behaviors:

I am way ahead of myself at times. And when I have to start telling myself "slow, K." even when I'm talking to family or whatever else then, I - I'm aware of what I'm doing. It's just, I have to verbally acknowledge it, even if it's in public just so I can make sure I slow myself down. It helps. It helps a whole lot. Even when I'm sitting by myself, and
I say "OK, K. get a grip on it for a minute. OK, K. Stop catch." I do this by myself, not just in front of people. It's not something an average ordinary person's supposed to have to do, but I find that it helps. [Respondent \#2004]

\section{Keeping a journal}

Writing down one's thoughts and feelings was another method of self-monitoring used by respondents to keep track of their moods and symptoms:

I keep a journal, and I'm trying to get a little more consistent at both in my journal and in taking my medication.

And, when I sit down to write, then I tend to remember so I'm trying to put myself back in a track to where I'm on a more ... cohesive basis. [Respondent \#2052]

In summary, the problem-based coping strategies used by respondents to adapt to the demands associated with managing BD included altering eating habits, managing mood stabilizing medications, keeping psychiatric appointments, as well as seeking knowledge on BD. Other problem-based coping strategies included socializing and self-monitoring.

Table 2 shows themes, descriptive codes, and illustrative quotations emerging from the discussion on coping with self-managing BD. These emotion-focused coping strategies were classified into four categories that reflected efforts toward decreasing the distress associated with managing BD: 1) distracting, 2) distancing, 3) helping others, and 4) seeking social support.

\section{Distracting}

Respondents cited many coping strategies that helped in distracting them from the stress associated with self-managing their chronic mental illness.

Table 2 Emotion-focused coping strategies for self-management among poorly adherent patients with bipolar disorder (BD) (N=2I)

\begin{tabular}{|c|c|}
\hline Themes and categories & Illustrative quotations from respondents \\
\hline \multicolumn{2}{|l|}{ Distracting } \\
\hline Spirituality & "I believe in my prayers that they give me strength, you know. I ask God to help me". [Respondent \#2009] \\
\hline Keeping busy & $\begin{array}{l}\text { "I'll watch the news and then I might turn on a little music for motivation, so I can clean up a little bit. And like } \\
\text { sometime I had the TV on, where I can have every commercial, I'll jump up and do something, just trying to stay busy, } \\
\text { I just keep moving. I don't stop and I don't wanna stop because then I'm sick, I'm scared I might make the wrong choice } \\
\text { or the wrong step or, you know, the wrong idea today. So I just move slow at it and do the best I can on a day to day } \\
\text { basis". [Respondent \#2004] }\end{array}$ \\
\hline \multicolumn{2}{|l|}{ Distancing } \\
\hline Denial/isolating & $\begin{array}{l}\text { "I isolate a lot. I try to stay away from people; basically just stay in my room. I just lock my doors and stay in the house } \\
\text { all the time". [Respondent \#2056] }\end{array}$ \\
\hline Modifying/avoiding & $\begin{array}{l}\text { "I got in the habit of breaking them in half (pills), and I take them that way and it made it easier for me to deal with it, } \\
\text { and it didn't just totally knock me out. Now, I can deal with them, as long as I take them that way". [Respondent \#2052] }\end{array}$ \\
\hline Helping others & "On the weekends, pretty much the weekends are mine. I'm a volunteer at an air museum". [Respondent \#20I7] \\
\hline Seeking social support & "If I have any problems, l'll call a friend or talk to a family member". [Respondent \#2007] \\
\hline
\end{tabular}




\section{Spirituality}

Some respondents cited spiritual domains, such as praying, meditation, and thinking positively as helping them cope with BD:

Every morning I wake up I have my coffee, preferably outside unless there's snow on the ground, and read a page of "Daily Bread" or "In Touch with Life," something spiritual. I just like to start my day like that. Just peace and thinking about how good the Lord is and things like that. Get up before my kids and do something peaceful. [Respondent \#2001] I try to think happy thoughts and just try to force myself not to get upset or angry at things. But a lot of times that don't work. So, that's why I try to take my medicine, when I'm supposed to. [Respondent \#2012]

\section{Keeping busy}

Playing music, reading, or watching TV were cited as coping strategies that helped respondent distract them from thinking about their BD:

Yeah, music, a lot of music: Gets me pumped. I think music is the best pill you can ever take. I love music, rock and roll, soft rock, country, I'm your girl. [Respondent \#2004]

I like to read. So, the reading takes me out of myself. You know I can go all over the world, just sitting right there in the living room. So, that helps. [Respondent \#2093]

I watch TV. I love to watch certain shows like John Wayne. I am a John Wayne and Clint Eastwood person. You know, that's my pick me up, any westerns you know. I mean those are things that get me like a burst to strength, you know what I'm saying. I really get going when I watch those shows! [Respondent \#2010]

And doing multiple solitary activities throughout the day, such as walking and household chores, helped some respondents focused and feeling "normal":

I don't like to be around crowds so I'll go home and I'll lock myself in and I'll clean my house or play some music or watch a good movie on TV or cook, to keep, you know, me focused and normal, quote-unquote. I try and keep busy because I don't like to think and I just can't be still. I have to keep it moving. [Respondent \#2004]

\section{Distancing Denial}

Some respondents, however, used denial as a coping strategy to distance themselves from the stress associated with managing their $\mathrm{BD}$ :
I'm actually terrified to death at times. When I get into the nurse's office or, going to the doctor, I'm really terrified to death and I don't know what they're going to tell me. And if they tell me something that means I'm crazy, I probably block it out and say no, it's not true. And I won't believe what they tell me. It's hard, it's difficult. [Respondent \#2052]

\section{Isolation}

Others isolated themselves from perceived stressful situations:

I just stay home and avoid stressful situations, which sometimes comes to me. I just stay to myself. You know somebody stops by to see me, that's beautiful. I enjoy being by myself. My cats keep me company and I stay out of trouble and it works. [Respondent \#2089]

\section{Modifying/avoiding}

As noted in Table 2, some respondents reported that they modified their intake of mood stabilizing medications to avoid certain side effects. Others avoided taking their medications because of the perceived stigma associated with having a mental illness:

If I start a relationship, I stop taking my medication because I don't want them to know what I got (BD). [Respondent \#2007]

It took a long time for me to take the medicine because I didn't want to be classified as having a mental illness because I thought I'd be ostracized [...] If my friends knew that I was taking medicine because I was bipolar, they'll say I am crazy. [Respondent \#2006]

\section{Helping others}

Helping others was another strategy used by some respondents to cope with their illness:

I cook, which is not a good thing, because I have to taste it and that puts weights on you. So I'm giving it to people or selling it. I do pound cakes, peanut butter cookies, and toll house cookies. [Respondent \#2093]

On weekends, I volunteer at an air museum. [Respondent \#2017]

\section{Seeking social support}

One method of coping with the management of BD symptoms was seeking support from "family and friends":

It took me several years to notice my mood swings and identify that I'm having them. Because I have a good support system that actually helps me identify them. 
Like, if I'm on the phone with my mom and I'm having a manic day or I'm going too fast or I'm hyper, she'll let me know. So, I can start focusing on my behavior, my speech, and everything like that. [Respondent \#2020]

Yet another way of seeking support for their illness was going to "support groups" where they felt comfortable with people who were facing the same problems:

I go to support groups like AA and NAA. Ah those are the people I'd rather be around when recovering so I go to group on like Monday. [Respondent \#2010]

In summary, the emotion-based coping strategies used by respondents to distract themselves from the stresses associated with managing BD, included spiritual or religious domains, as well as solitary activities that kept them feeling "focused and normal". Although denial, isolation, and avoidance were used by some as coping strategies to distance themselves from stressful situations, others cited helping others and seeking support from friends, families, and support groups, as helpful in coping with their mental illness.

To gain insight into what kind of help our respondents wanted from their health care providers in helping them cope with managing their $\mathrm{BD}$, we asked them to tell us what their providers could do to assist them. As can be observed, improved communication and listening skills, help with coping skills, help with medication adherence, and finally, there was a desperate need by respondents to have their providers help them in finding and facilitating access to resources, such as social services, housing, and transportation:

When you have a limited income, it's hard to find housing. It's hard to find programs where you can go to be able to get some type of help. They (providers) don't give you any avenues of resources. They'll tell you "well, go down to the welfare building." Welfare building cannot help you [...]. It's even more frustrating when you get down there and you have to deal with the social workers, supervisors, the people down there, the people waiting in the lobby. It's crazy and it's another thing, more stress added on to you. [Respondent \#2011]

Get me transportation so I can keep my appointments! [Respondent \#2002]

\section{Discussion}

To the best of our knowledge, this is the first reported qualitative study to address the gap between coping theory and the clinical use of coping strategies in a well-characterized sample of poorly adherent patients with BD. Although these individuals acknowledged that they were poorly adherent with BD medications, they still exhibited a variety of coping behaviors that involved both pharmacological and nonpharmacological treatments. It has been amply demonstrated that simply telling a person to take their medication is not likely to result in long-term and consistent adherence. ${ }^{24,25}$ To begin to address medication-taking and consistent adherence, which is known to be foundational to good outcomes in $\mathrm{BD}$, it is important to understand how individuals conceptualize their role in health behaviors and use this as a starting point in partnering with patients to optimal engagement in care. Table 3 summarizes suggestions from this study sample on how health care providers of poorly adherent BD patients can help improve their coping and self-management. Being able to characterize an individual's coping behaviors can facilitate being able to enhance and support coping behaviors that are likely to promote optimal outcomes and modify or replace more maladaptive coping with more effective coping strategies.

Table 3 Poorly adherent bipolar patients' suggestions on how health care providers can help support self-management ( $\mathrm{N}=2 \mathrm{I}$ )

\begin{tabular}{|c|c|}
\hline Themes and categories & Illustrative quotations from respondents \\
\hline Personalize care & $\begin{array}{l}\text { "I'm not just another number, another file. Take me in personally and really try to see what I need to do, what I } \\
\text { need to make myself better [...]" [Respondent \#2007] }\end{array}$ \\
\hline Better communication & $\begin{array}{l}\text { "[...] whatever time you have with your patient, whatever if it's } 15 \text { minutes, } 20 \text { minutes, really try to listen to } \\
\text { what they're sayin' and, maybe that will make it better for them and for me [...]" [Respondent \#200I] }\end{array}$ \\
\hline Consistency in providers & $\begin{array}{l}\text { "I'd like to have the same person that I see each time that I come. I want it to be the same person. If that person } \\
\text { isn't available, I'll wait a month for an appointment [...]" [Respondent \#2093] }\end{array}$ \\
\hline Help with coping skills & $\begin{array}{l}\text { "Help me learn ways to cope with the symptoms, try to help find a way to keep me on a schedule". } \\
\text { [Respondent \#2005] }\end{array}$ \\
\hline Help with medication adherence & $\begin{array}{l}\text { "Trying me on different medications and giving me some information that would explain how you're supposed } \\
\text { to feel so I can understand if it's working for me [...]" [Respondent \#2089] } \\
\text { "[...] I would ask her if she would consider you know letting me try something else (medication). You know } \\
\text { they always have new stuff that come out". [Respondent \#2008] }\end{array}$ \\
\hline Help with finding resources & $\begin{array}{l}\text { "[...] besides talking to her, see if I can talk with uh, like a social worker, whenever I needed to, or on a weekly } \\
\text { basis". [Respondent \#20I7] }\end{array}$ \\
\hline
\end{tabular}


Several observations about the data deserve mention. First, the Model of Stress and Coping, used as a framework for the study, provided a comprehensive approach that allowed us to evaluate an individual's process of coping with their chronic mental illness. Second, consistent with the model, participants utilized a combination of problem-focused and emotion-focused coping strategies as illustrated by our qualitative findings. Coping behaviors were sometimes positive and helpful, whereas other times behaviors were helpful in the short run (avoiding people relieves one of having to deal with stigma), but harmful in the long-run (social isolation and marginalization). Some participants in the study used problem-focused strategies (reminders/prompts, keeping to a schedule) to help in managing their mood-stabilizing drugs, but under certain stressful situations, they would sometimes reappraise their situation and use emotion-focused strategies. Reappraisal is the process of continually evaluating, changing, or relabeling earlier primary or secondary appraisals as a situation evolves. ${ }^{18}$ As an example, one participant in the study usually took her mood-stabilizing medications on schedule but, in an effort to cope with the perceived stigma associated with her mental illness, stopped taking them when she was involved in a relationship. This could be an example of both external stigma (negative reactions from others) and internal stigma (internalized negative beliefs about one's self). In a meta-analysis of internalized stigma in people living with mental illness, Livingston and $\mathrm{Boyd}^{26}$ found a striking negative relationship between internalized stigma and psychosocial variables (hope, self-esteem, empowerment), medication adherence, and a positive relationship with psychiatric symptom severity. In clinical settings, understanding an individual's goals (taking medication) and how these goals might be derailed by life circumstances (perceive need to hide one's mental health condition to minimize stigmatizing attitudes or behaviors) is critical in partnering with patients in the recovery process. In the case of the individual who stopped taking medications when she was in a serious relationship, psychotherapeutic efforts might address the risks and costs of denying need for psychiatric care (relapse, possible hospitalization) and how these potential consequences would be likely to impact a long-term intimate relationship.

Problem-focused coping appears to be particularly relevant to self-management in $\mathrm{BD}$, where hallmarks of the illness include cyclical changes in motor behaviors and sleep-wake patterns. As noted in the illustrative quotes, learning to identify behaviors that could signal impending BD manic relapse (reduced need for sleep, excessive energy, rapid and pressured speech) takes time and focused attention. Evidence-based effective therapies for people with
BD include Interpersonal and Social Rhythm Therapy ${ }^{27}$ and Life Goals Intervention, ${ }^{28}$ which support self-awareness of biological rhythms, healthy planning response, and longterm positive health outcomes. Additional evidence-based strategies include psychoeducation ${ }^{29}$ and new approaches using web-based mobile technologies. ${ }^{30}$ In the case of poorly adherent BD patients, helping individuals to recognize personal triggers or relapse signs and implement healthy problem-focused coping may be an opportunity to change what is otherwise a likely poor prognosis and trajectory.

Although our findings have implications for viewing coping strategies as a possible mediator of the effects of psychosocial interventions with this population, there are some limitations. Patients with BD who receive care in other treatment settings, or those who have less severe or disabling illness, may have different experiences in coping with this chronic mental illness. The small convenience sample and the fact that the study was conducted in a single urban area in the USA may also limit transferability of the study findings. At the same time, the focus on poorly adherent patients facilitated an understanding on coping strategies for self-management among those who are most in need for psychosocial interventions. These limitations are offset, to some extent, by the use of rigorous qualitative research methods described in this study. ${ }^{19-23}$ The self-report method is direct, versatile, and yields information that would be difficult, if not impossible, to gather by other means.

\section{Conclusion}

This qualitative study provided a first step in evaluating the coping strategies used by high-risk patients to selfmanage their BD. Further qualitative and quantitative studies are needed to explore the fluid nature of the coping process in patients with BD and to take into account many of the situational factors that can influence appraisal and reappraisal of perceived threat. According to the Theory of Stress and Coping, ${ }^{17,18}$ what occurs during appraisal processes determines subsequent emotions and coping behaviors.

\section{Acknowledgments}

Research reported in this publication was supported by the National Institute of Mental Health of the National Institutes of Health under Award Number R01MH093321. Support was also received from the Clinical and Translational Science of Cleveland, UL1TR000439, from the National Center for Advancing Translational Sciences (NCATS) component of the National Institutes of Health and NIH roadmap for Medical Research. The content is solely the responsibility of the authors and does not necessarily represent the official views of the National Institutes of Health. 


\section{Disclosure}

Jennifer Levin, receives partial salary support from the following research grants: Reuter Foundation, Reinberger Foundation, Woodruff Foundation, Janssen Scientific Affairs, and National Institutes of Health (NIH).

Martha Sajatovic has received research grants within the past 3 years from the following organizations: Pfizer, Merck, Ortho-McNeil Janssen, Janssen, Reuter Foundation, Woodruff Foundation, Reinberger Foundation, National Institute of Health (NIH), and Centers for Disease Control and Prevention (CDC). Martha Sajatovic is also a consultant for Bracket, Prophase, Otsuka, Pfizer, Amgen, and Sunovion, and receives royalties from Springer Press, Johns Hopkins University Press, Oxford Press, UpToDate, and Lexicomp. The authors report no other conflicts of interest in this work.

\section{References}

1. Murray CJ, Lopez AD. Global mortality, disability, and the contribution of risk factors: Global Burden of Disease Study. Lancet. 1997;349: 1436-1442.

2. Hirschfeld RMA, Calabrese JR, Weissman M. Lifetime prevalence of bipolar I and II disorders in the United States. Presented at: 155th Annual Meeting of the American Psychiatric Association; May 18-23; 2002; Philadelphia, PA.

3. American Psychiatric Association. Practice guideline for the treatment of patients with bipolar disorder (revision). Am J Psychiatry. 2002; 159:1-50.

4. Keck PE Jr, Perlis RH, Otto MW, et al. The Expert Consensus Guidelines: Treatment of Bipolar Disorder 2004. A Postgraduate Medicine Special Report. Minneapolis, MN: McGraw Hill; 2004:1-120.

5. Goodwin GM, Young AH. The British Association for Psychopharmacology guidelines for treatment of bipolar disorder: a summary. J Psychopharmacol. 2003;17(4 Suppl):3-6.

6. Yatham LN, Kennedy SH, O’Donovan C, et al. Canadian Network for Mood and Anxiety Treatments (CANMAT) guidelines for the management of patients with bipolar disorder: consensus and controversies. Bipolar Disord. 2005;7(Suppl 3):5-69.

7. Sajatovic M, Valenstein M, Blow FC, et al. Treatment adherence with antipsychotic medications in bipolar disorder. Bipolar Disord. 2006;8: 232-241.

8. Miziou S, Tsitsipa E, Moysidou S, et al. Psychosocial treatment interventions for bipolar disorder: a systematic review. Ann Gen Psychiatry. 2015;14:19. doi:10.1186/s12991-015-0057-z.

9. Lazarus RS. Coping theory and research: past, present, and future. Psychosom Med. 1993;55:234-247.

10. Pearlin LI, Schooler C. The structure of coping. J Health Soc Behav. 1978;19:2-21.

11. Thoits P. Stress and health: major findings and policy implications. J Health Soc Behav. 2010;51(Suppl):S41-S53.
12. Park C, Iacocca M. A stress and coping perspective on health behaviors: theoretical and methodological considerations. Anxiety Stress Coping. 2014;27(2):123-137.

13. Skinner E, Edge K, Altman J, Sherwood H. Searching for the structure of coping: a review and critique of category systems for classifying ways of coping. Psychol Bull. 2003;129:216-269.

14. Post RM, Leverich GS. The role of psychosocial stress in the onset and progression of bipolar disorder and its comorbidities: the need for earlier and alternative modes of therapeutic intervention. Dev Psychopathol. 2006;18:1181-1211.

15. Kapczinski F, Vieta E, Andreazza AC, et al. Allostatic load in bipolar disorder: implications for pathophysiology and treatment. Neurosci Biobehav Rev. 2008;32:675-692.

16. Polkinghorne DE. Phenomenological research methods. In: Valle RS, Halling S, editors. Existential-Phenomenological Perspectives in Psychology. New York, NY: Plenum Press; 1989:41-60.

17. Lazarus RS. Psychological Stress and the Coping Process. New York, NY: McGraw-Hill; 1966.

18. Lazarus RS, Folkman S. Psychological Stress and the Coping Process. New York, NY: Springer; 1984.

19. Creswell JW. Qualitative Inquiry \& Research Design: Choosing Among Five Approaches. Thousand Oaks, CA: Sage; 2007:57-62.

20. Ezzy D. Qualitative Analysis: Practice and Innovation. New York, NY: Routledge; Crows Nest, NSW: Allen \& Unwin; 2002.

21. Strauss A. Qualitative Analysis for Social Scientists. New York, NY Cambridge University Press; 1988.

22. Marshall C, Rossman G. Designing Qualitative Research, 3rd ed. Thousand Oaks, CA: Sage; 2003.

23. Moustakis C. Phenomenological Research Methods. Thousand Oaks, CA: Sage; 1994.

24. Velligan DI, Weiden PJ, Sajatovic M, et al. Strategies for addressing adherence problems in patients with serious and persistent mental illness: recommendations from the expert consensus guidelines J Psychiatr Pract. 2010;16(5):306-324.

25. Sajatovic M, Davies M, Bauer MS, et al. Attitudes regarding the collaborative practice model and treatment adherence among individuals with bipolar disorder. Compr Psychiatry. 2005;46(4):272-277.

26. Livingston JD, Boyd JE. Correlates and consequences of internalized stigma for people living with mental illness: a systematic review and meta-analysis. Soc Sci Med. 2010;71(12):2150-2161.

27. Frank E, Soreca I, Swartz HA, et al. The role of interpersonal and social rhythm therapy in improving occupational functioning in patients with bipolar I disorder. Am J Psychiatry. 2008;165(12):1559-1565. doi:10.1176/appi.ajp.2008.07121953.

28. Kilbourne AM, PostEP, Nossek A, Drill L, Cooley S, Bauer MS. Improving medical and psychiatric outcomes among individuals with bipolar disorder: a randomized controlled trial. Psychiatr Serv. 2008;59(7):760-768. doi: 10.1176/appi.ps.59.7.760.PMID:18586993.

29. Colom FM, Vieta J, Sanchez-Moreno R, et al. Group psychoeducation for stabilized bipolar disorders: 5-year outcome of a randomized clinical trial. Br J Psychiatry. 2009;194:260-265.

30. Hidalgo-Mazzei D, Mateu A, Reinares M, et al. Self-monitoring and psychoeducation in bipolar patients with a smart-phone application (SIMPLe) projects: design, development and studies protocols. $B M C$ Psychiatry. 2015;15:52. doi:10.1186/s1288-015-04337-6.
Patient Preference and Adherence

\section{Publish your work in this journal}

Patient Preference and Adherence is an international, peer-reviewed, open access journal that focuses on the growing importance of patient preference and adherence throughout the therapeutic continuum. Patient satisfaction, acceptability, quality of life, compliance, persistence and their role in developing new therapeutic modalities and compounds to optimize

\section{Dovepress}

clinical outcomes for existing disease states are major areas of interest for the journal. This journal has been accepted for indexing on PubMed Central. The manuscript management system is completely online and includes a very quick and fair peer-review system, which is all easy to use. Visit http://www. dovepress.com/testimonials.php to read real quotes from published authors. 